\title{
Desafíos de la antropología de la religión en América Latina para abordar el tema del cristianismo entre pueblos indígenas
}

\author{
Daniel Pacheco
}

\author{
UMCA-ULACIT \\ dpachecoh@yahoo.com
}

\begin{abstract}
Master en Teología Católica con énfasis en Teología Fundamental de la UNED y egresado de maestría en Antropología de la UCR. Actualmente, es profesor de las áreas de Métodos de Investigación y Ética Profesional en la UMCA-ULACIT y de Historia del Arte en UIA. Además, es investigador y colaborador voluntario en la Asociación Humánitas, Hogar de la Esperanza en San José, donde trabaja con población en riesgo social por adicciones y VIH-SIDA. Algunas de sus publicaciones recientes son: "Nuevos alcances de la ética en investigación a partir de la ética de la liberación" (Reflexiones, UCR, Vol. 91, 2012); y "Cuerpo y sexualidad desde una teología crítica y emancipadora" (Espiga, UNED Vol. XI, 2012).
\end{abstract}

Resumen: El artículo presenta un análisis desde la antropología de la religión sobre las relaciones entre cristianismo y pueblos indígenas, analizando algunos documentos y declaraciones relacionados con el tema, tanto de parte de autoridades cristianas como de comunidades indígenas. Se busca, a futuro, fomentar el diálogo y la construcción mutua entre pueblos indígenas e iglesias cristianas, para fortalecer las posibilidades de desarrollo autónomo de los pueblos indígenas de América Latina.

Palabras clave: Antropologia de las religiones, indigenismo, Iglesia Latinoamericana, teología india.

Abstract: The present article shows an analysis from the anthropology of religion about the rela-
tions between Christians and indigenous populations, reviewing documents and declarations about
the subject, from the authorities of catholic churches and from the indigenous people by it. We look
for a future dialogue and mutual construction between church's and indigenous cultures, to streng-
th the options of autonomous development of the indigenous cultures in Latin America.
Keywords: Anthropology of religions, indigenous, Latin-American church, indigenous theology.

Cuadernos de Antropología 2014, 24(1), 21-36

Recibido: 23-06-2013 / Aceptado: 04-06-2014

Revista del Laboratorio de Etnología María Eugenia Bozzoli Vargas

Escuela de Antropología, Universidad de Costa Rica

http://revistas.ucr.ac.cr/index.php/antropologia

ISSN 2215-356X

(c) (i) (-) Cuadernos de Antropología está bajo una licencia Creative Commons Attribution-NonCommercial-ShareAlike 3.0 


\section{Introducción}

El presente ensayo retoma temas claves de la antropología de la religión en América Latina. Si bien existen varios estudios sobre el tema de lo religioso en medio de diversos grupos culturales en nuestro continente, creo necesario confrontar diversas perspectivas teóricas sobre la forma en que el cristianismo ha penetrado en las culturas más antiguas de América Latina. En este caso específico, pretendo realizar un diálogo entre la teología cristiana y la antropología de las religiones. Estas dos grandes tradiciones intelectuales - una con más de dos milenios de historia, otra con poco más de un siglo de existir- tienen mucho que aportar en el tema del desarrollo en las comunidades indígenas, campesinas y urbanas de nuestro continente.

Es importante el diálogo entre dos disciplinas que no suelen encontrarse en contextos de debate o diálogo académico, a mi parecer, porque ambas (teología y antropología) suelen encasillarse a sí mismas en áreas aparentemente disímiles (la una cree vivir entre lo etéreo y lo intocable; la otra se dice hija del barro y la tierra), sin darse cuenta ambas que tratan sobre el mismo tema: el ser humano y sus distintas percepciones y reacciones sobre lo que tiene a su alrededor. Otras veces, ambas abarcan el mismo tema o situación social, pero sus discursos se presentan como diametralmente opuestos, aun partiendo de los mismos datos o textos.

En la primera parte del presente ensayo, retomaré algunos conceptos clásicos y contemporáneos de la antropología de las religiones, para optar por un acercamiento de esta disciplina adecuado para abarcar problemas como el cristianismo entre los indígenas, o la religiosidad en las zonas más pobres del continente.

En la segunda parte, realizaré un breve estudio histórico y teológico del problema de las relaciones entre cristianismo y pueblos indígenas en América Latina. Revisando su historia será posible hacer una propuesta para caminar ante la complicada, dolorosa y esperanzadora relación que han compartido estas dos cosmovisiones.

\section{¿Qué antropología de la religión debemos buscar hoy en nuestro contexto?}

Para realizar un estudio en este campo, es necesario definir un paradigma de acercamiento al "misterio" que implica lo sagrado en una cultura específica. Este paradigma de acercamiento al fenómeno religioso inicia con el aporte de la antropología simbólica cultural que suele señalar a Clifford Geertz como su principal referente. El acercamiento de este teórico prioriza el papel y las opiniones de los actores que crean la cultura cotidianamente. Este autor se da a la tarea de acuñar un nuevo concepto de religión que retome los aportes teóricos de los clásicos de sus predecesores, ampliándolos con su propia perspectiva. Geertz acuña la siguiente definición de religión: 
Una religión es: 1) un sistema de símbolos que obra para 2) establecer vigorosos, penetrantes y duraderos estados anímicos y motivaciones en los hombres 3) formulando concepciones de un orden general de existencia, y 4) revistiendo estas concepciones con una aureola de efectividad tal que 5) los estados anímicos parezcan de un realismo único (Geertz, 2005, p. 89).

Creo que lo más destacable de la propuesta de Geertz (2005) es dejar de lado las concepciones positivistas de la religión que consideran los sistemas de creencias como un simple espejo de las prácticas sociales, económicas y culturales de la sociedad, y la considera como miembro activo y creador dentro del cosmos social. Esta propuesta, influenciada por Weber, y cercana a Eliade, sugiere que lo religioso es un sistema cultural interdependiente que da sentido a la existencia humana. Efectivamente, esta es una institución que actúa en dos vías, tanto influenciando y configurando la sociedad como dejándose configurar por los demás elementos del orden social. La labor sintética-simbólica de lo religioso es lo que le hace fundamental para conocer el ethos de un pueblo. En la insitucionalización de lo sagrado se reflejan las más íntimas palabras y cosmovisiones de un grupo, allí es donde las personas suelen recurrir para resguardar y referir una parte importante de su patrimonio subjetivo y simbólico, y es el referente del ordenamiento moral y ético de la mayoría de habitantes de muchas culturas.

La religión describe la realidad de un pueblo como es, y al mismo tiempo como debería ser, revelando tanto lo más oculto e íntimo de los pueblos, como sus expresiones culturales y tradiciones más elocuentes. Es un sistema simbólico, pero lo es solo para el observador externo. Para el "que está allí", para el Otro con el cual me relaciono como sujeto antropológico, lo religioso es verdad, si bien no una verdad en el sentido científico-cartesiano, pero es sin lugar a dudas "Es" y es algo, que se puede considerar objetivamente como verdadero. Por eso dice Geertz (2005) que "los estados anímicos parecen de una realismo único"; es decir, los fenómenos, las acciones, los eventos asociados a lo religioso son tan reales para quienes los viven, que sin lugar a dudas crean verdad grupal, hechos históricos y, al mismo tiempo, responden a los más álgidos eventos de la historia.

A pesar de la riqueza de esta vertiente clásica, es necesario señalar una carencia en su análisis. Ella sigue en la línea de los clásicos al privilegiar el estudio de las "manifestaciones espirituales, o de lo sagrado en los grupos "tribales" o "tradicionales" (o lo que en su momento determinada corriente llamó "culturas primitivas"). Sin embargo, la religiosidad en las sociedades modernas ha sido tema del que se ha ocupado primordialmente por otras disciplinas en otros momentos (por ejemplo, la sociología de las religiones o la teología misma); como consecuencia de ello, los estudios urbanos contemporáneos de antropología de la religión son escasos.

La misión del antropólogo contemporáneo no debe ser sencillamente describir, analizar y disecar sistemas de símbolos, sino comprender cómo este sistema simbólico influye en los procesos de cambio social, cómo colabora en la construcción de subjetividades y de intersubjetividades, cómo convoca y crea capital social, y cómo distorsiona u oculta determinadas partes de la realidad que los creyentes desean omitir. 
Si bien, en un primer momento, los grandes teóricos ubicados en un contexto epistemológico influenciado por la posmodernidad nos ofrecieron nuevas herramientas y perspectivas para analizar estos fenómenos, hoy, creo necesario replantear los alcances de nuestra ciencia. Podemos partir de las herramientas metodológicas y epistemológicas del paradigma simbólico de la antropología, pero debemos ir más allá en los alcances de nuestros estudios. Esto es sumamente importante ante las preguntas que la antropología de las religiones debe plantearse en América Latina, y particularmente en torno al problema de los pueblos indígenas en relación con el cristianismo. ¿Los pueblos más antiguos de América asimilan, aceptan, modifican o rechazan el cristianismo? ¿En qué grado ejecutan cada una de estas posibles opciones? ¿Qué percepción interna tienen respecto de sus creencias tradicionales, ante el reto de la comunicación y la globalización? Una pregunta nueva, poco discutida, es ¿cómo influye la acepción de lo religioso por parte del investigador?, ¿existe algún riesgo, limitante o ventaja cuando el investigados es abiertamente creyente, ateo o indiferente respecto de lo religioso?, o cuando profesa especial devoción o particular rechazo alguna institución religiosa encontrada en el campo. Es necesario encontrar pistas para ofrecer múltiples respuestas a estas preguntas.

La relación con otras ciencias también es un tema relevante ante estas preguntas. Desde la teología y la eclesiología se ha dado un abordaje histórico muy rico para la comprensión del fenómeno de las relaciones entre cristianismo y pueblos indígenas, en especial ante temas que tocaré más adelante, como la iglesia india y la teología india.

¿Qué perspectiva debe asumir una antropología de la religión latinoamericana ante los retos planteados? Deseo retomar una propuesta sugerida por un clásico de la antropología latinoamericana indigenista. Es la propuesta de la teoría del control cultural de Guillermo Bonfil (1988) desarrollada a principios de los años 80. En esta se maneja el tema del origen y las decisiones en torno a los recursos culturales, los cuales son definidos por el autor como "...todos los componentes de una cultura que resulta necesario poner en juego para realizar todas y cada una de las acciones sociales: mantener la vida cotidiana, satisfacer necesidades, definir y solventar problemas, formular y tratar de cumplir aspiraciones".

De acuerdo con Bonfil (1988), los elementos culturales y las decisiones en torno a estos pueden ser tanto propios como ajenos. Es entonces cuando se manifiestan diferentes formas de vivir la cultura en cada pueblo. La cultura autónoma, fundamental para mantener la identidad colectiva, se da cuando los recursos culturales y la capacidad de decisión sobre estos pertenecen al propio pueblo. En completa oposición a esta situación se encuentra la cultura impuesta, cuando ni los elementos culturales ni las decisiones pertenecen al pueblo. Este caso se da en momentos de dominación como el colonialismo. La cultura apropiada implica que los elementos culturales ajenos son puestos bajo el control de un pueblo. En muchas ocasiones estos procesos concluyen en una apropiación que desemboca en una cultura autónoma; por ejemplo, cuando los países latinoamericanos se apropiaron, diversificaron y reprodujeron el idioma español como propio. Por último, el ámbito de la cultura enajenada es definido por Bonfil (1987) como un campo de lucha permanente. En este caso, los recursos culturales están ahí, son parte de la cotidianidad del grupo, pero 
este ha sido privado de la capacidad de elegir sobre ellos. Un ejemplo de esto es la apertura de una mina o una represa en un bosque, o hasta la misma pérdida de la fuerza de trabajo (Bonfil, 1987). Esta teoría es explicada por el autor en un cuadro sintético (Cuadro 1).

De acuerdo con el paradigma teórico antropológico que he asumido para abarcar el tema de la antropología de la religión en América Latina (la antropología cultural simbólica), creo que, al analizar estos temas entre los pueblos más antiguos de nuestro continente, nos enfrentamos ante una situación de análisis de manejo del recurso cultural de la religión, lo sagrado y el capital simbólico.

La religión, las creencias y los sistemas éticos que les son inherentes son claramente un elemento cultural de los pueblos que abarcan elementos materiales, de organización, de conocimiento, simbólicos y emotivos.

Por eso, es fundamental hacerse junto con Bonfil (1987) la pregunta de cómo se maneja entre los pueblos indígenas el elemento cultural religioso. ¿Bajo qué circunstancias históricas la religión se convierte en un elemento autónomo, enajenador o impuesto? La historia de América Latina ha demostrado muchos matices en este sentido, siendo que las iglesias ocupan espacios y posiciones diferentes, de acuerdo con las diversas dinámicas históricas y culturales. Muchas veces hemos constatado que el cristianismo es una imposición forzosa; otras veces, comprobamos que puede ser un elemento liberador, emancipador, que consolida y define la identidad desde los pueblos mismos.

Es posible interpretar que este cuadro de teoría del control cultural de Bonfil (1987) expone un caso de cultura impuesta al hablar de cristianismo entre pueblos indígenas. Sin duda, la llegada del cristianismo, y en general de la mayoría de los elementos culturales europeos a América durante la conquista y colonia, constituyen elementos de una cultura impuesta. Sin embargo, cuando luego de varias generaciones se ha adoptado este paradigma, queda la duda sobre si la asimilación a través de las generaciones no nos coloca dentro de un caso de cultura apropiada. A pesar que el cristianismo continúa siendo impuesto forzosamente en muchos sitios, existen procesos en los cuales los pueblos han decidido apropiarse de los elementos culturales y enriquecerlos. Me atrevo a afirmar que en muchos sitios el cristianismo ha sido apropiado de forma enriquecedora en varios pueblos. Luego de muchos siglos de dolorosa inculturación forzosa y aniquilación de costumbres ancestrales indígenas, es posible vislumbrar portillos para la dignidad cultural en la esencia de un mensaje cristiano actual.

Cuadro 1. Los ámbitos de la cultura en función del control cultural.

\begin{tabular}{clc}
\hline ELEMENTOS CULTURALES & Decisiones PROPIAS & Decisiones AJENAS \\
\hline Propios & Cultura AUTÓNOMA & Cultura ENAJENADA \\
Ajenos & Cultura APROPIADA & Cultura IMPUESTA \\
\hline
\end{tabular}

Fuente: tomado de Bonfil 1988 (p. 24) 
El siguiente apartado revisará brevemente los puntos más importantes de esta historia de relaciones entre cristianismo y pueblos indígenas americanos, para ofrecer mayor claridad a estas situaciones aparentemente contradictorias.

\section{Los desafíos antropológicos de pensar lo cristiano entre los pueblos indígenas}

El cristianismo llegó en 1492 a América. Esta historia empieza con condiciones sumamente violentas para los pueblos indígenas. Los ibéricos trajeron entonces dos ideas claras, aparentemente con igual peso en la mentalidad de los conquistadores: primero, la conquista de las riquezas y recursos; segundo, la motivación ideológica y religiosa de la conquista de las almas y la conversión de nuevos cristianos ${ }^{1}$. Desde muy temprano, las Indias se llenaron de frailes, Iglesias, parroquias y misiones. Incluso los primeros argumentos de Cristóbal Colón participaban de este doble sentido de la conquista en lo ideológico y económico:

Crean Vuestras Altezas que en el mundo todo no puede haber mejor gente, ni más mansa. Deben tomar vuestras altezas grande alegría porque luego los harán cristianos y los habrán enseñado en las buenas costumbres de sus reinos, que más mejor gente ni tierras no puede ser, y la gente y la tierra en tanta cantidad, que yo no sé cómo escriba (Diario de Cristóbal Colón, segunda parte; citado por Mires, 1989, p. 35).

La teología de la esclavitud desarrollada durante estos primeros años en América tiene varias posibles fuentes, tales como la noción de un profeta cristiano precedente, o la legitimación de la conquista bajo la premisa de la salud espiritual de los indígenas y la salvación de sus almas. Esta premisa fue suficiente para la matanza -santificación del alma- y la conquista militar -la cruz entraba por la fuerza apoyada por estrategias militares-. Muchas ideas políticas, económicas y científicas apoyaban la tesis de la inferioridad natural del indio y la necesidad de castigar sus pecados, su idolatría y su creencia en demonios (Mires, 1991). Cierta reciprocidad irónica se deja ver en la economía de la salvación en este contexto. Los indígenas pierden sus costumbres y su oro, pero a cambio reciben los supuestos beneficios de la "civilización" europea.

El principal defensor de las tesis de esclavitud, conquista y conversión forzosa de los indios es el Doctor Juan Ginés de Sepúlveda (1490-1573). Este hombre puede ser considerado, sin duda, un "genio"

1 Es posible establecer un debate sobre la validez o fuerza de cada una de estas motivaciones. Para varios autores, la búsqueda de riquezas fue el motivo primordial y único de la conquista, para posteriormente introducir el argumento de la fe por la fuerza por motivos ideológicos y soteriológicos. La hipótesis de la doble motivación espiritual-material de la conquista, sigue primordialmente el argumento del autor F. Mires (1991). 
renacentista, con una vasta formación en teología, historia, filosofía y derecho. Con todos estos conocimientos, se destacó por ser el más conocido defensor de las teorías de la esclavitud de los indios, a favor de las clases nacionalistas y clasistas europeas. La verdadera herejía de Sepúlveda, según Mires (1991), es que adapta el derecho canónigo y la teología para justificar los fines económicos y políticos de la esclavitud. El argumento irreductible para justificar la violencia y la esclavización es la Ley Natural: "Hay otras causas de justa guerra... una de ellas es someter por las armas, si por otro camino no es posible, a aquellos que por su condición natural deben obedecer a otros y rehúsan su imperio. Los filosóficos más grandes declaran que esta guerra es justa por ley de naturaleza" (G. de Sepúlveda; citado por Mires, 1991, p. 68). Para Sepúlveda y sus contemporáneos, la conquista es una obra evangélica y civilizadora. Los indios, como seres incapaces de gobernarse a sí mismos, más bien deben estar agradecidos por los beneficios que la civilización les proporciona. Las razones de la barbarie de los indios parecen ser evidentes ante los ojos renacentistas: guerras constantes entre ellos, sacrificios humanos, prácticas sexuales irregulares y ausencia de propiedad privada. Llama la atención el hecho irónico que estos argumentos se esgrimen desde la Europa posmedieval, donde las guerras, los asesinatos, las relaciones patriarcales y la injusticia en el reparto de las tierras eran cotidianos (Mires, 1991, p. 72).

Las ideas esclavistas de Sepúlveda, aunque aparezcan como excepcionalmente injustas desde nuestra perspectiva histórica, eran nada más la consolidación de las prácticas cotidianas ocurridas en las indias. Si analizamos estos procesos solamente desde sus implicaciones económicas, materiales, políticas e históricas, nos daremos cuenta que, en el fondo, la conquista y la colonia eran un sistema para consolidar repartimientos de tierra, tributos en especie y oro, y la encomienda.

Por otro lado, es necesario recordar que existieron entonces intelectuales que también abogaron por el respeto, la dignidad y la vida de los indígenas de las tierras recién descubiertas. El caso más famoso y evidente es el de Bartolomé de las Casas, quien perteneció a una escuela de clérigos que abogaba a favor de los indios. Entre otros líderes que luchaban no solo contra una visión ideológica y religiosa, sino contra el poder militar, político y económico de los encomenderos, se encentraba el obispo Juan Zumárraga en México, y otros menos conocidos como fray Antonio de Montesinos, el padre Miguel de Salamanca, Matías Paz, fray Miguel Arcos, y varios otros religiosos dominicos. Su número era reducido, pero su presencia en las cortes y en la producción intelectual era intensa (Mires, 1991). La obra de Casas era no solamente piadosa, sino que era también una denuncia de la injusticia del trabajo esclavizante y la encomienda:

Ninguna otra pestilencia pudo el diablo inventar para destruir todo aquel orbe, consumir y matar todas aquellas gentes y despoblar como se ha despoblado tan grandes y tan poblados reinos, y ésta sólo bastaba para despoblar al mundo, como fue la invención del repartimiento y la encomiendas de aquellas gentes, que repartieron y las encomendaron a los españoles como si se las encomendaran a todos los diablos, o como hatajos de ganados entregados a hambrientos lobos (De las Casas, “Tratados"; citado por Mires, 1991, p. 141). 
De las Casas ofrece un sistema de denuncia que abarca no solo lo ético, moral y religioso, su obra y la de sus compañeros es una clara denuncia del sistema económico y político claramente injusto. Esta obra continúa vigente varios siglos después, cuando muchas de las atrocidades denunciadas por el sacerdote siguen vigentes, o a lo sumo han cambiado su forma de manifestación.

Desde muy temprano en la historia de la conquista, la ideología religiosa cristiana, de la mano con el poder económico, político y militar, ha contribuido a la represión, la violencia y la esclavitud de los pueblos más antiguos de nuestro continente. Existen múltiples manifestaciones concatenadas en la vida social, cultural, económica, política, educativa, y la construcción de una determinada vivencia particular de la Iglesia y el cristianismo. Un dato particular que llama la atención sobre las condiciones del desarrollo del cristianismo, y particularmente del catolicismo en América Latina, es que luego de 500 años de desarrollo de la Iglesia, no existe ningún obispo o cardenal de orígenes indígenas en ninguna parte de América. Esto es particularmente interesante ante el hecho de que otros continentes, con una historia similar de penetración violenta de cristianismo y cultura occidental, sí han logrado implantar sus propios líderes religiosos nativos. Mientras que en la iglesia africana, asiática y de Oceanía, la nota dominante es que los obispos, líderes e inclusive los representantes en el vaticano son fieles representantes de la cultura de sus pueblos. En América, los únicos que han logrado destacar han sido los que pertenecen a una cultura mucho más "blanca", sin que los indígenas o los afroamericanos puedan acceder al liderazgo. ¿Es esto una señal positiva o negativa de la autonomía y las decisiones de estos pueblos por mantener sus raíces? ¿O es un indicador más de discriminación y exclusión?

Para responder a estas preguntas, podemos analizar el movimiento llamado "teología indígena" (o india) desarrollado en las últimas décadas. Este movimiento es descrito por el obispo Lozano (2001), de Zacatecas, México, como sigue:

Es la Teología que brota de las semillas del Verbo que se encuentran en las culturas indígenas. Se basa en la experiencia de Dios que se tiene en estas culturas. Compara los elementos culturales indígenas con el Cristianismo. Es la expresión de las religiones indias precolombinas. Es la manera vivencial cómo se comporta el pueblo indio. Cuando el mito habla de cosas trascendentes se convierte en Teología... La "Teología india" es un acto segundo con relación a la fe que es el acto primero. Se entiende como sistematización de experiencias religiosas. Es el esfuerzo de entender al indígena en su estar en el mundo. La "Teología india" es comunicar cómo el pueblo indio experimenta a Dios. Es una y variada, tiene como punto de referencia la tierra. Las Teologías indias son creativas, festivas, de resistencia a la hegemonía eclesiástica, a la imposición cultural, al colonialismo, a la marginalización económica, a la globalización, privilegian la transmisión oral, comienzan y terminan con la tierra. Se expresa triplemente: mitos, ritos y símbolos propios, que se echan a perder si se pretende cristianizarlos (p. 160).

http://revistas.ucr.ac.cr/index.php/antropologia 
La llamada "teología indígena" podría ser considerada tanto como la reflexión sistematizada de las religiones tradicionales de los pueblos indígenas, como la reformulación del pasado y el presente de estos pueblos desde el cristianismo. En ambos casos, el movimiento representa un reto extraordinario no solo para la antropología de las religiones, sino para toda ciencia social que se preocupe por las relaciones culturales, la desigualdad, y las dinámicas de interacción entre lo rural- urbano, lo indígena, lo mestizo y lo blanco, etc. Una perspectiva de teología indígena que interprete la tradición desde cultural ancestral desde el cristianismo permite releer la Biblia y encontrar en ella datos que permitan fortalecer la espiritualidad de los pueblos indios, o ayudar en situaciones de liberación, tanto espiritual como social. Al mismo tiempo, también es posible utilizar estos caminos para eliminar, alienar e imponer elementos culturales, sociales y económicos exógenos a los pueblos indígenas.

La antropología y la etnología deben prestar mucha atención a estos procesos, que implican una sensibilidad particularmente delicada en el diálogo entre culturas, la ponderación de los aportes de diversas tradiciones, el escuchar a las comunidades y actores, el valorar el pasado histórico y la comprensión integral del papel de la religión dentro del cosmos social ${ }^{2}$.

Un caso ejemplar a seguir en torno a este tema es el aporte del sacerdote zapoteco Eleazar López, quien ha realizado una gran labor con muy pocos recursos en el tema de las relaciones teológicas entre cristianismo y creencias indígenas. La obra de este autor (que a la vez es actor) parte del hecho de que el punto de partida y llegada, tanto de la teología cristiana como de la espiritualidad indígena, es el mismo: una experiencia de fe en Dios, que se manifiesta en un segundo momento bajo determinadas formas culturales específicas. Es en este segundo momento cuando se da la imposición violenta del cristianismo sobre lo indígena, a pesar de tener un origen común:

Dado que en las teologías cristianas, más reconocidas y apoyadas institucionalmente, se ha enfatizado la comunicación de la vivencia trascendente mediante el uso de un lenguaje discursivo y racionalista, y en las teologías indígenas el acento es la misma vivencia de la trascendencia, que se comunica en lenguaje simbólico, pareciera que entre ellas hubiera barreras infranqueables. Pero en realidad no existen tales barreras; ya que ambas teologías comparten la misma realidad trascendente, que es Dios, el mismo sujeto creyente que es el pueblo pobre y, a me-

\footnotetext{
2 No es casual que esta tendencia se haya desarrollado en los años 60 y 70. En esta época tanto la sociedad como la Iglesia Latinoamericana sufrieron fuertes cambios, impulsados por las revoluciones globales (Mayo 68, Revolución cubana, Tlatelolco, etc.) y el cambio de pensamiento que implicó el Vaticano II en la Iglesia. No se podría comprender el cambio en la teología fuera de este contexto histórico, donde el movimiento llamado "Teología de la Liberación" permitió que esta espiritualidad saliera de las cuevas y las montañas, y llegara en muchos casos hasta ciertos espacios menores de las jerarquías eclesiales (Tanto en la iglesia católica como en algunas protestantes). Se dio así un apoyo a esta(s) nueva(s) teología(s) en la conferencia del CELAM de Medellín 1968, con roles importante como el de los Obispos Mons. Leonidas Proaño (Ecuador), Mons. Samuel Ruiz (Chiapas, México), Mons. Pedro Casaldáliga (Brasil) entre otros.
} 
nudo, los mismos caminos andados en cuanto a la comunicación de la experiencia teologal (López, 1997a).

Para este autor, los principales tropiezos de la teología indígena a la hora de relacionarse con el cristianismo son que la teología cristiana, como reflexión, suele chocar con el concepto de la teología como vivencia, propio de la visión indígena. Además, existe aún cierto miedo al término "indio", el cual es visto como foráneo y ofensivo, aunado a una confusión de conceptos, pues las creencias indígenas y sus manifestaciones no se consideran claramente como teología, sino como cosmovisiones, mitologías; y no se consideran religiones, sino meras espiritualidades (López 1997b).

Para establecer un camino real de diálogo, es necesario abandonar viejas estructuras de pensamiento coloniales, y encontrar los puntos en común del camino de ambas perspectivas religiosas, partiendo del hecho fundamental que ambas perspectivas tiene el mismo sujeto: los pueblos indígenas. López (1997a) señala que el camino teológico de los pueblos más antiguos de América tiene mucha diversidad, varias fases, múltiples manifestaciones, y un nivel de complejidad considerable. Esta riqueza no suele ser considerada por ningún actor occidental, los cuales generalmente observan una homogeneidad ingenua en la riqueza de la producción religiosa indígena (López, 1997a).

Al respecto del tema de las relaciones entre estas dos tradiciones, el obispo Lozano Barragán propone procesos de diálogo cultural en los cuales se intercambien valores y no conceptos, y no se imponga lo cristiano-occidental a las religiones y tradiciones amerindias. Desde la perspectiva de este autor, existe el peligro grave de mezclar símbolos, conceptos y vivencias. En lugar de mezcla o yuxtaposición, se debe buscar proceso de intercambio y aprendizaje.

De la « Teología india» brotará una nueva iglesia india, con sus nuevos valores, ministerios e instituciones. La evangelización de los misioneros fue incompetente... la Iglesia durante 500 años fue un error, una imposición cultural opresiva. La Iglesia sospecha del indígena y sospecha de su veracidad... La Iglesia debe reconocer que hay varios caminos de salvación; debe reconocer que el camino que Ella propone no es más que uno de tantos. El Cristianismo debe abdicar de su pretensión de ser el camino único, sin que esto signifique que abdica de Jesucristo... El papel de las iglesias es acompañar a los pueblos indios en la formación de la conciencia indígena... La cultura indígena es en sí salvadora. La Iglesia debe 
renunciar a ser Madre y debe alinearse como hermana de los pueblos indígenas. La Iglesia institucional debe dejar de ser maestra y tornarse alumna del pueblo indio (Lozano, 2001, p. 168).

Este tipo de teologías se correspondió con procesos que se desarrollaban día tras día entre las montañas, las selvas y los valles de todo el continente, donde florecieron pastorales creadas por y para los indígenas. Estos movimientos partieron del rescate de la espiritualidad y la cosmovisión indígena, y el empoderamiento de ellas a partir de la Estructura Eclesial ${ }^{3}$. De este modo, el trabajo fue paralelo entre diversos niveles de la Iglesia, tanto fieles indígenas y campesinos, laicos, así como pastores, sacerdotes, teólogos y obispos.

Lamentablemente, esta postura teológica no es dominante en la interacción entre Iglesia y pueblos indígenas. En la práctica, la imposición sin diálogo de la ideología y la fe cristiana se siguen llevando a cabo día tras día en distintas partes del continente, a través de diversos procesos de evangelización. Por ejemplo, en 2006 en la diócesis de San Cristóbal de las Casas, México, donde existe una mayor influencia de la teología indígena, la Santa Sede decidió intervenir y reprender al obispo titular, por su apoyo constante a lo que el vaticano calificó como una "iglesia autóctona". Esto no es otra cosa que una iglesia separada del orden cultural venido de Roma. Además de la práctica de reflexiones y experiencias espirituales indígenas relacionadas con lo cristiano, esta diócesis se caracterizó por la ordenación constante de sacerdotes casados bajo el ministerio del diaconado permanente. Esta práctica es aceptada por el Vaticano, pero, en esta zona en específico, los sacerdotes casados aumentaron en número y participación pastoral. Asimismo, la mayoría de los diáconos permanentes son de ascendencia indígena, lo cual es elemento de más sospecha para el Vaticano. En su carta enviada en el 2006 al obispo de San Cristóbal de las Casas, el Cardenal Arinze, prefecto de la Congregación para el Culto divino y los Sacramentos, menciona lo siguiente:

Continúa estando latente en la Diócesis la ideología que promueve la implementación del proyecto de una Iglesia Autóctona. En este sentido, la Reunión Interdicasterial se ha pronunciado por una suspensión de eventuales ordenaciones de

3 Entre otros movimiento, vale la pena resaltar el trabajo de realizado en el país de Ecuador de la Ecuarunari o Confederación Kichwa (Ecuador Runakunapak Rikcharimuy, "Movimiento de los Indígenas del Ecuador”), en la sierra; y la Confienae (Confederación de las Nacionalidades Indígenas de la Amazonia Ecuatoriana) en la zona del Amazonas, los cuales son producto de trabajo pastoral de la Iglesia Católica, y han dado múltiples luchas en lo social y cultural. 
diáconos permanentes hasta que se haya resuelto el problema ideológico de fondo... el diaconado supone una vocación personal, no una designación comunitaria sino una llamada oficial de la Iglesia; requiere una formación intelectual sólida; orientada por la Sede Apostólica. Para contribuir a sanear la vida eclesial, desde el inicio se ha pedido y se continúa a indicar, abrir la diócesis a otras realidades propias de la universalidad de la Iglesia Católica, para ayudarla a salir del aislamiento ideológico mencionado. Por último, cabe subrayar que, alimentar en los fieles expectativas contrarias al Magisterio y a la Tradición, como en el caso de un diaconado permanente orientado hacia el sacerdocio uxorado (casado), coloca a la Santa Sede en la situación de tener que rechazar las distintas peticiones y presiones, y, de este modo, se le hace aparecer como intolerante (ACI, 2006).

En gestos específicos como este se denota que los auténticos esfuerzos por dialogar e intercambiar experiencias de fe entre cristianismo occidental-europeo y pueblos americanos han sido aniquilados en décadas recientes por las autoridades cristianas europeas, las cuales siguen considerando al indígena como "sospechoso" y "sectario".

Un lugar primordial donde se denota esta actitud es en el discurso inaugural del papa Benedicto XVI (en ese momento en ejercicio) durante la V Conferencia general del episcopado latinoamericano en Aparecida Brasil, donde el eurocentrismo, la superioridad ideológica y la ausencia de cualquier posibilidad de diálogo horizontal con el "otro" son evidentes:

La fe en Dios ha animado la vida y la cultura de estos pueblos durante más de cinco siglos. Del encuentro de esa fe con las etnias originarias ha nacido la rica cultura cristiana de este continente expresada en el arte, la música, la literatura y, sobre todo, en las tradiciones religiosas y en la idiosincrasia de sus gentes, unidas por una misma historia y un mismo credo, y formando una gran sintonía en la diversidad de culturas y de lenguas. ¿Qué ha significado la aceptación de la fe cristiana para los pueblos de América Latina y del Caribe? Para ellos ha significado conocer y acoger a Cristo, el Dios desconocido que sus antepasados, sin saberlo, buscaban en sus ricas tradiciones religiosas. Cristo era el Salvador que anhelaban silenciosamente... En efecto, el anuncio de Jesús y de su Evangelio no supuso, en ningún momento, una alienación de las culturas precolombinas, ni fue una imposición de una cultura extraña. Las auténticas culturas no están cerradas en sí mismas ni petrificadas en un determinado punto de la historia, sino que están abiertas, más aún, buscan el encuentro con otras culturas, esperan alcanzar la universalidad en el encuentro y el diálogo con otras formas de vida y con los elementos que puedan llevar a una nueva síntesis en la que se respete siempre la diversidad de las expresiones y de su realización cultural concreta... La utopía de 
volver a dar vida a las religiones precolombinas, separándolas de Cristo y de la Iglesia universal, no sería un progreso, sino un retroceso. En realidad sería una involución hacia un momento histórico anclado en el pasado. La sabiduría de los pueblos originarios les llevó afortunadamente a formar una síntesis entre sus culturas y la fe cristiana que los misioneros les ofrecían (Benedicto XVI, 2007, p. 7. Resaltado por parte del autor).

Desde las más altas esferas del cristianismo se continúa menospreciando el pasado indígena, se sigue negando el hecho fundamental de la conquista violenta y la imposición de la fe y se sigue consolidando el argumento de que los indígenas deben estar agradecidos por el regalo de la civilización y el cristianismo. Esto sucede luego de más de 500 años de evidencia histórica a pesar de los avances en el diálogo que germinó a finales del siglo XX.

Los obispos de América Latina, en la redacción final del documento de la conferencia episcopal de Aparecida, fueron un poco más condescendientes con el asunto cultural en el continente:

"El Evangelio llegó a nuestras tierras en medio de un dramático y desigual encuentro de pueblos y culturas..." (ACI, 2006, p. 4). "Lamentablemente estos sufrimientos se han prolongado 500 años hasta nuestros días. Las comunidades indígenas y afroamericanas en muchas ocasiones, no son tratadas con dignidad e igualdad de condiciones..." (ACI, 2006, p. 65).

Este retorno y revalorización que intentan hacer los obispos del continente respecto del aspecto cultural parecen tener una justificación en el análisis de una supuesta crisis de la cultura "blanca-occidental" manifiesta en las zonas urbanas de Latinoamérica y en muchos otros sectores. Según el análisis de los grandes líderes cristianos, es ésta una cultura plena de individualismo, fragmentación, consumismo, relativismo, acumulación insultante de riquezas en manos de unos pocos, que causa el creciente empobrecimiento de muchos, violencia, de depredación y explotación indiscriminadas de los recursos naturales. Ante esta situación, la milenaria cultura indígena se ve como un camino de reflexión que podría ofrecer una respuesta ante esta situación: "Los indígenas constituyen la población más antigua del Continente. Están en la raíz primera de la identidad latinoamericana y caribeña... (ACI, 2006, p. 88). Posteriormente, los obispos de la conferencia resaltaron la valiosa vivencia comunitaria y la relación con la naturaleza de los pueblos indígenas de nuestro continente: "De ellos valoramos su profundo aprecio comunitario por la vida, presente en toda la creación, en la existencia cotidiana y en la milenaria experiencia religiosa, que dinamiza sus culturas" (ACI, 2006, p. 529).

Lamentablemente, en ninguna parte del documento final de Aparecida se menciona la "Teología India" ni la "Teología Afro", ni “Teología de Liberación”, ni "Teología Feminista”, ni "Ecoteología”, que sin duda aportarían mucho en la búsqueda de una auténtica "inculturación” de la Iglesia en el mundo indígena. 
En ese sentido, podemos percibir que existen ciertos resabios aún sobre otorgar la dignidad y la voz a las mujeres, los indígenas, los negros y a la naturaleza, esos “otros” que nos conforman, y esas "minorías” que son mayoría en este continente.

A la luz de estos versos de documentos históricos y cartas oficiales de la Iglesia Católica, se observa una "tensión" teológica, entre un mundo conservador, eurocéntrico, que pretende mostrarse como homogéneo; y una realidad diversa, llena de actores que exigen tener voz, pero que aún padecen discriminación de sus auténticas exigencias y que reclaman la visualización de un doloroso pasado de exclusión, violencia y muerte. En otras palabras, en la teología cristiana actual se perciben las mismas condiciones que en muchos otros espacios sociales en América Latina: una tensión entre revalorización de lo indígena, lo diverso, lo femenino, lo ecológico, lo afro; y una sociedad occidental, blanca, urbana que tiene aún resistencia a aceptar las necesarias reivindicaciones de los "otros". Desde esa perspectiva, es necesario encontrar caminos para un diálogo religioso efectivo, una reivindicación auténtica desde los pueblos por sí mismos, que vayan de la mano con reivindicaciones en lo educativo, económica, laboral, cultural, etc.

\section{Reflexiones finales}

El cristianismo no solo ha sido impuesto de forma muchas veces violenta y denigrante a los pueblos más antiguos de las tierras americanas, sino que, una vez aceptado, la discriminación cultural parece continuar por medio de discretos mecanismos de exclusión. Parece evidente la relación que existe entre diferencias culturales, exclusión del poder político y económico, limitación de las libertades de educación y autogestión, y poco acceso a decisiones y conocimiento en las diversas iglesias cristianas.

La imposición de patrones culturales occidentales en cuanto a idioma, vestido, alimentación y educación, parecen ir de la mano con la imposibilidad que tienen los pueblos indígenas de manifestar su religiosidad verdaderamente inculturada sin recibir críticas y limitaciones por parte de los líderes religiosos.

La verdadera libertad y los verdaderos derechos plenos de los pueblos serán alcanzados cuando exista igualdad de culto, acceso al conocimiento y las decisiones respecto de la religión que decidan abrazar. En el caso del cristianismo, sea católico o de tradición protestante, es necesario avanzar en el diálogo teológico e institucional, para que el acceso a la fe de los pueblos americanos, vaya de la mano con un auténtico respeto a las decisiones, y una verdadera garantía de libertad cultural. Sin duda alguna, estos procesos de religiosos debe ir de la mano con la solución de problemas relacionados con la discriminación y la marginalidad que padecen miles de personas en cuanto a acceso a trabajo, vivienda, educación, salud, poder político y decisiones económicas. 
Respecto a los aspectos metodológicos y etnográficos de la antropología de la religión, creo que compartir ciertos elementos de una creencia religiosa permite construir un puente subjetivo con los "nativos creyentes", de una forma similar en que comprender un idioma o compartir una condición de género, ideología o política nos permite acceder mucho mejor a la cultura de un pueblo o un individuo. Sin duda, existe también el riesgo de perder objetividad en la investigación, para lo cual es necesario contar con la asesoría y lectura de pares profesionales externos y una clara matriz de variables de análisis y diagnóstico de la realidad observada. Durante varias experiencias etnográficas en comunidades tanto indígenas como no indígenas, he podido construir esta clase de puentes con mis informantes gracias a compartir elementos culturales como la religión.

El sacerdote indígena Eleazar López afirma que existe esperanza de diálogo y crecimiento común entre cultura indígena y tradición cristiana. A los ojos de este autor-actor, el mundo indígena, a pesar de sus múltiples problemas, ha irrumpido cada vez más fuertemente en la sociedad y en la Iglesia, a través de luchas activas y unidas a lo largo del continente, no solo con indígenas, sino con otras voces como la ecología y las mujeres. Como resultado de esto, poco a poco dentro de la iglesia existen espacios nuevos de diálogo, abandonando la intolerancia y recelo, a pesar que en ocasiones parecen haber retrocesos (López, 1997b).

La historia de América Latina demuestra que las instituciones cristianas han sido en repetidas ocasiones un instrumento de dignificación de los pueblos y de acceso a medios para ejercer los derechos humanos efectivamente; sin olvidar jamás que la Iglesia fue participe del mayor genocidio de la historia de la humanidad, cuando millones de personas, pueblos, lenguas y culturas fueron exterminados bajo la cruz y la espada; y también que grupos cristianos han apoyado dolorosas acciones de guerra, violencia y represión en años recientes.

El innegable papel clave de las instituciones cristinas dentro de la cultura de los pueblos latinoamericanos debe ir de la mano con un verdadero respeto de las diferencias culturales y con el apoyo de todas las demás áreas de la sociedad civil. La antropología de las religiones auténticamente latinoamericana debe acompañar, conocer, traducir y participar de estos diálogos y encuentros. Nuestra ciencia también debe denunciar los abusos, las imposiciones y la violencia ejercida en contra de los pueblos más antiguos. Es un verdadero reto para los antropólogos hoy tener una producción teórica que honre la diversidad y complejidad de estos temas, al mismo tiempo que camina y aprende junto con los indígenas y las comunidades cristianas.

Busquemos una Antropología cultural que sepa ocupar un papel activo, tanto en la academia como en las montañas, los campos y las ciudades, para fomentar el diálogo, el conocimiento y la dignidad humana. Y que sea san Juan Diego Cuauhtlatoatzin, símbolo del diálogo entre dos mundos unidos y distintos, quien continúe dando un ejemplo vivo desde el dolor, la opresión, la esperanza y la alegría de los sus descendientes de todas las culturas. 


\section{Referencias bibliográficas}

ACI Prensa (2006). La Santa Sede dice no a iglesia indígena y a sacerdocio casado en América Latina. Recuperado el 11 de octubre de 2012, de http://www.mercaba.org/CONGREGACIONES/CULTO/ iglesia_indigena_sacerdocio_casado.htm.

Benedicto XVI, P.P. (2007). Discurso inaugural de la conferencia de Aparecida. En CELAM, V conferencia general del episcopado latinoamericano y del Caribe, Documento conclusivo (7-24). Bogotá: Ed. San Pablo, Bogotá.

Bonfil, G. (1987). Los pueblos indios, sus culturas y las políticas culturales. En, N. Garcia-Canclini (ed.), Politicas culturales en América Latina (pp. 89-125). México D. F.: Enlace - Grijalbo.

Bonfil, G. (1988). La teoría del control cultural en el estudio de procesos étnicos. Anuario Antropológico, $86,13-53$.

CELAM, (1987). V conferencia general del episcopado latinoamericano y del Caribe, Documento conclusivo. Bogotá: Ed. San Pablo, Bogotá.

Geertz, C. (2005). La interpretación de las culturas. Barcelona: Gedisa.

López, E. (1997a). Caminos de la teología india. Recuperado el 20 de abril de 2012, de http://usuaris.tinet. cat/fqi_sp02/docum_sp.htm.

López, E. (1997b). Dios Camina entre los mayas. Recuperado el 20 de abril de 2012, de http://usuaris. tinet.cat/fqi_sp02/docum_sp.htm.

Lozano, J. (2001). La teología india. En, Ecclesia Catholica. Pontificia Commissio pro America Latina, Actas, realidades problemas, perspectivas o propuestas pastorales en orden a la Nueva Evangelización a la luz de la Exhortación Apostólica Ecclesia in America (pp.159-175). Vaticano: Librería Editrice Vaticana.

Mires, F. (1991). El discurso de la indianidad. San José: DEI.

Mires, F. (1989). En el nombre de la cruz. Discusiones teológicas y políticas frente al holocausto de los indios. San José: DEI. 